\title{
¿Es otra cosmopolítica posible? ${ }^{1}$
}

\section{Mario Blaser}

Cátedra de Investigación Canadiense de Estudios Aborígenes

Universidad Memorial de Terranova

mblaser@mun.ca

\begin{abstract}
La cosmopolítica es ahora la situación común para todos los colectivos. No existe un mundo común, y aun así, no obstante, debe ser compuesto [Cosmopolitics is now the common situation for all collectives. There is no common world, and yet it has to be composed, nonetheless.]
\end{abstract}

Bruno Latour, Anthropology at the Time of the Anthropocene.

El 28 de enero de 2013, el gobierno de Terranova y Labrador anunció la prohibición de la caza de caribú (o renos) durante cinco años ${ }^{2}$. Esta prohibición fue impuesta después de que numerosos estudios mostraran que la población de la manada del río George (GRH, por sus siglas en inglés) había mermado vertiginosamente, de 800000 individuos en 1990 a solo 27000 en $2012^{3}$. Aunque sin estar seguro de las causas, el gobierno provincial entendía que la continua captura de caribúes («el recurso») no era sostenible, incluso para las comunidades indígenas innu e inuit que viven en Labrador. Al día siguiente del anuncio, Prote Poker, el Gran Jefe de la nación innu, declaró que la prohibición era injustificable; que los ancianos innu no estaban de acuerdo con ella porque constituía una amenaza a su modo de vida y que las comunidades iban a continuar cazando como lo habían hecho siempre ${ }^{4}$. Entre otras preocupaciones, el rechazo de los innu a aceptar la prohibición estaba basada en la insistencia de los cazadores y ancianos expertos, quienes veían la caída de la población de la manada como un síntoma del deterioro de la relación entre los innu y Kanipinikassikueu, el «señor»o «espíritu guardián» de los atîku (la palabra que los innu usan para referirse a lo que los eurocanadienses llaman

Versión original en inglés: Blaser, Mario (2016). Is Another Cosmopolitics Possible? Cultural Anthropology, 31(4), 545-570. Traducido por Carolina Tytelman. Instituto de Investigaciones Sociales y Economicas, Universidad Memorial; y Olatz González Abrisketa, Universidad del País Vasco.

2 Ver http://www.releases.gov.nl.ca/releases/2013/env/0128n08.htm. Visitada agosto 13, 2013. Ver http://www.releases.gov.nl.ca/releases/2012/env/0816n03.htm. Visitada agosto 5, 2013.

Ver http://www.cbc.ca/news/canada/newfoundland-labrador/story/2013/01/29/nl-innu-caribou-hunt-129.html. Visitada agosto 19, 2013. 
caribú $)^{5}$. El grado en el que los protocolos de caza - tales como el uso y descarte de los huesos y el reparto de carne del atîku, entre otras prescripciones- se cumplen determina la salud de la relación y la voluntad de Kanipinikassikueu de continuar entregando animales, y en general, de «bendecir» a los innu. En ese punto, cazadores y ancianos llevaban quejándose durante varios años de que las generaciones más jóvenes de innu no estaban siguiendo estos protocolos y les reclamaban que se volvieran a comprometer con ellos. En este contexto, para cazadores y ancianos, la prohibición haría imposible reparar la relación con atîku y su espíritu guardián. En síntesis, mientras que para los encargados de vida silvestre en el gobierno provincial cazar podría significar la desaparición del caribú, para los cazadores y ancianos innu el no poder cazar siguiendo sus propios protocolos casi seguramente significaría la desaparición del atîku'

Pensar en las posibles maneras de lidiar con este conflicto aparentemente irresoluble nos conduce al concepto de cosmopolítica. Este concepto, inicialmente propuesto por Isabelle Stengers (1997), difiere de la versión kantiana de cosmopolitanismo, según el cual un cosmopolita es aquel que rechaza alianzas parroquiales y abraza el mundo común (el cosmos) como el fundamento para solucionar las diferencias entre humanos. En esta concepción, el cosmos es trascendente y no requiere discusión. Lo que se debate (y debe ser resuelto) son las diferentes visiones que, dadas sus lealtades a sus culturas y tradiciones, los humanos tienen sobre el cosmos. Retornando a nuestro ejemplo, una llamada cosmopolita a resolver los desacuerdos entre los innu y el gobierno provincial apelaría a que los participantes abandonen sus respectivas perspectivas parroquiales y se enfoquen en cambio en aquello que es común a ambas: la «cosa» que les preocupa, a la que unos llaman caribú y otros atîku. En una discusión con Ulrich Beck - y movilizando la noción de cosmopolítica de Stengers-, Bruno Latour (2004a) señala que los humanos no entran en conflictos con sus perspectivas sobre las «cosas»; entran en ellos junto con las «cosas» no humanas que los hacen actuar. En este sentido, caribú y atîku no referirían a perspectivas diferentes sobre la misma «cosa» sino a cosas completamente diferentes (aunque relacionadas). Así, para Stengers y Latour, el problema con el cosmopolitanismo es que asume un cosmos ya unificado, un mundo único (la «cosa» común), cuando realmente habitamos un pluriverso. Este pluriverso demanda una cosmopolítica.

El señor también puede ser llamado Papakashtshihku o Katipinimitautsh (ver Armitage, 1992).

Como mostraré, la desaparición del atîku implica una amenaza a toda una serie de relaciones

y prácticas que muchos innu ven como fundamentales para su existencia. 
Stengers relata que el término cosmopolítica se le ocurrió cuando se encontró a sí misma corriendo el riesgo de transformar un tipo de práctica particular en una clave universal neutra. Escribe: «[1] as ciencias llamadas modernas serían una manera de responder a la pregunta política por excelencia: ¿quién puede hablar de qué, quién puede ser el portavoz de qué, representar qué?» (Stengers, 2014, p. 20) El riesgo, dice, era olvidar que la categoría de política con la que ella estaba trabajando forma parte de una tradición particular y, por lo tanto, decidió articularla con el término cosmos. Lejos de referirse al cosmos «tal como pudiese pensarlo en una tradición particular» (2014, p. 21) en su uso, el cosmos «designa lo desconocido de estos mundos múltiples, divergentes; las articulaciones de las que podrían llegar a ser capaces» $(2014$, p. 21). La referencia a las posibles articulaciones que mundos divergentes podrían desarrollar conecta nuevamente el cosmos a la política de dos maneras: (i) interrumpe su universalidad (la política es «nuestra» fórmula para constituir «nuestro» mundo en común, no sabemos los procedimientos que otros mundos han ideado para constituirse a sí mismos como «comunes»), y (ii) enlista a la política para explorar la posibilidad de que esos mundos divergentes, articulándose unos con otros, se conviertan en un mundo común ${ }^{7}$. Latour sucintamente captura lo que logra la invención de Stenger con la palabra cosmopolitica,

La presencia de cosmos en cosmopolítica resiste a la tendencia de que política signifique el dar-y-tomar en un club humano exclusivo. La presencia de politica en cosmopolítica resiste a la tendencia de que cosmos signifique una lista finita de entidades que considerar. Cosmos protege contra la clausura prematura de política, y política contra la clausura prematura de cosmos (Latour, 2014, p. 46, énfasis en el original).

Concebida así, la cosmopolítica habla de la intersección de dos tópicos que han animado últimamente los debates antropológicos: por un lado, bajo las etiquetas de multiespecies y nuevo materialismo (Kirksey y Helmreich, 2010; Coole y Frost, 2010), la reevaluación de la agencia como un atributo distribuido a lo ancho de ensambles heterogéneos de humanos $y$ no humanos, y por otro lado, bajo la etiqueta del «giro ontológico» (Holbraad y Pedersen, 2014; Kohn, 2015), la reevaluación de la alteridad radical como una relación de múltiples ontologías

7 Stengers dice que el cosmos es parte del «problema de una ecología de las prácticas que hermana nuestras ciudades que inventaron la política, y aquellos lugares donde el asunto de la clausura y transmisión ha inventado otras soluciones por si mismo» $(1997$, p. 75 , traducción del autor del francés). 
o mundos en lugar de culturas. Cada una de estas intervenciones coincide con una «política» y un «cosmos» que son expandidos por la cosmopolítica. Aun así, continúan corriendo el riesgo de quedar clausuradas si no se conectan entre ellas. Por ejemplo, como Gad, Jensen y Winthereik (2015) argumentan, algunos académicos inscritos en el giro ontológico les dan demasiado peso a los conceptos de los informantes humanos, pero le prestan poca atención al rol de los no humanos $^{8}$. A la inversa, DiNovelli-Lang (2013) y yo mismo (Blaser, 2014) hemos señalado que los tropos de multiespecies y nuevo materialismo tienden a depender en gran medida de las ciencias naturales como voceras de los no humanos admitidos en la política y, por lo tanto, continúan delineando un cosmos con un número finito de entidades legítimas 9 . El tipo de conflicto que he descrito más arriba produce un cortocircuito en cualquier clausura prematura de «política» y «cosmos», incluso si estos son expandidos, y por lo tanto nos fuerzan a mantener los dos componentes de la cosmopolítica en tensión.

Pero más allá de los debates académicos, manteniendo abierta la pregunta de quién y qué podría componer el mundo común, la cosmopolítica ofrece una manera de comprender este tipo de conflictos que evita las dificultades de lo que yo llamo el problema de la «política razonable». Me extenderé sobre esto más adelante; por ahora baste con indicar que el problema con la política razonable es que, al definir por adelantado qué tipo de diferencias están en juego en estos conflictos (como hace el cosmopolitanismo), refuerza un estado de cosas en el cual algunas preocupaciones (presentadas como «perspectivas») pueden ser marginadas porque - tal como la afirmación de que el «señor» de los atîku se los da a los innu - son consideradas irreales, y por lo tanto, irracionales o irrelevantes.

Al imaginar el mundo común como un resultado posible, en lugar de como un punto de partida, la cosmopolítica interrumpe el rápido recurso de descartar preocupaciones en función de su supuesta carencia de realidad. En efecto, el valor principal de la «propuesta cosmopolítica» está «en que habrá "ralentizado" los razonamientos, en que habrá creado la ocasión de una sensibilidad un poco diferente de los problemas y situaciones que nos mueven» (Stengers, 2014, p. 18, comillas en el original). Y aun así, como el epígrafe de Latour indica, el mundo común debe ser compuesto. Por lo tanto, aunque Latour y Stengers denotan distintos sentidos de urgencia, para ellos la cosmopolítica continúa orientada a la

8 Algunos de estos académicos incluyen a Viveiros de Castro (2012), Philippe Descola (2013), Martin Holbraad (2007) y Morten Pedersen (2007).

$9 \quad$ Ejemplos incluyen el trabajo de Donna Haraway sobre especies de compañía (2008, pero ver 2015), Anna Tsing (2012) y Karen Barad (2007). 
composición del mundo común, incluso cuando insisten en la falta de garantías para semejante proyecto.

En este artículo sostengo que semejante orientación limita la capacidad de la cosmopolítica para hacer frente al tipo de conflictos que he descrito más arriba. Para probar mi argumento voy a someter la cosmopolítica a una prueba pragmática mediante una «lectura» del concepto difractada a través de materiales etnográficos (Barad, 2007, p. 200). Mi preocupación principal no es apoyar o rechazar el concepto de cosmopolítica, sino más bien ver qué elementos de él son útiles para abordar este conflicto como un problema político-conceptual y en qué puntos la etnografía sugiere que hay una necesidad de expandir el concepto. Primero voy a presentar un resumen general del problema de la política razonable, resaltando aquellos aspectos por los que la cosmopolítica, y la semiótica-material en la que se basa, parecen ofrecer algunos asideros. Luego voy a la «prueba» propiamente dicha, explorando el grado en que la cosmopolítica es un concepto fructífero para los conflictos que me preocupan. Finalmente, siguiendo los contornos de lo que la cosmopolítica parece incapaz de tratar adecuadamente en mis materiales etnográficos, avanzo una serie de sugerencias para otra cosmopolítica.

\section{EL PROBLEMA DE LA POLÍTICA RAZONABLE}

Lo que llamo el problema de la política razonable parece típicamente etnográfico: cómo evaluar expresiones que al investigador le parecen contrafácticas. El ejemplo clásico sería la declaración de los nuer de que los mellizos son pájaros cuando el investigador sabe que son hermanos humanos. Usualmente la solución para este problema entraña explicar cómo y por qué los nuer podrían pensar que los hermanos mellizos humanos son pájaros. Martin Holbraad (en Carrithers et al., 2010) ha señalado que semejante resolución refleja las suposiciones previas del analista de que diferentes representaciones culturales de «mellizos» están en juego. Implícita en esta suposición está la afirmación de que el analista esta en lo cierto (es decir, que los mellizos son en realidad hermanos humanos) mientras que los nuer se equivocan (es decir, producen representaciones culturales de los mellizos humanos que están «fuera de lugar» y requieren explicación). El problema de la política razonable se vuelve más visible cuando, en lugar de ocurrir en el dominio de los encuentros etnográficos, las «expresiones contrafácticas» ocurren en el dominio de los conflictos donde asuntos de vida o muerte están en juego, o cuando ciertos tipos de vidas son considerados posibles mientras otros no. Conflictos que circundan entidades que los estados y corporaciones tratan 
como «recursos» y que otros toman como personas no humanas o suprahumanas con las cuales mantienen relaciones sociales diversas - como es el caso de los innu con atîku y su espíritu guardián — son por lo tanto más que aptos para hacer evidente el problema de la política razonable.

En otro lugar, y mediante una discusión inspirada etnográficamente, yo (así como otros colegas) he tratado los problemas conceptuales que este tipo de conflictos representan. Marisol de la Cadena, por ejemplo, ha argumentado que estos conflictos ponen en primer plano un desafío conceptual para la «política usual». La presencia de personas no humanas en política desautoriza «la separación entre "Naturaleza" y "Humanidad", sobre la que se ha basado históricamente la teoría política que "nuestro mundo" asume» (2010, p. 342). A su vez, yo he sostenido que al utilizar el concepto de cultura para tratar de empoderar a aquellos que ponen en primer plano el estatus de las entidades como personas no humanas, nos encontramos ante un impase (Blaser, 2013a). Al presentar a las personas no humanas como «cultura» (tradiciones, creencias, etc.) acabamos tratando esos conflictos como epistemológicos, es decir, como conflictos entre «perspectivas acerca del mundo» (una perspectiva cultural «ve» personas mientras la otra «ve» recursos). Esta movida reinstala y refuerza los supuestos ontológicos implícitos en la «constitución moderna» (es decir, la división naturaleza / cultura y los binarios que le siguen en cascada). La alternativa, he sostenido, es que en lugar de tratar esta clase de conflictos como «conflictos culturales» los tratemos como «conflictos ontológicos» (Blaser, 2009, 2013b).

El centro del problema aquí es que el supuesto moderno de un mundo y múltiples perspectivas sobre ese mundo es constitutivo de lo que llamo la «política razonable» y de sus operaciones. Brevemente, la política razonable opera sobre la base de transformar «diferencias» en «diferencias entre perspectivas del mundo». Las diferencias convertidas en diferencias de perspectivas son susceptibles de ser ordenadas jerárquicamente de acuerdo con supuestos grados de equivalencias entre las representaciones que distintas perspectivas posibilitan y el propio mundo fáctico o real. Este ordenamiento, a su vez, hace posible considerar ciertas perspectivas irrelevantes $\mathrm{y}$, en consecuencia, descartables $\mathrm{o}$, peor, destruibles (ver Povinelli, 2001, 2002). El proceso de atribuir facticidad es extremadamente disputado. Sin embargo, el poder de la política razonable descansa precisamente en su capacidad de establecer los términos de contestación (o desacuerdo) como un asunto de perspectivas compitiendo por su facticidad. Esto es particularmente problemático para aquellos que no se adhieren a la epistemología derivada del supuesto ontológico de la existencia de un mundo «real»: como ellos no están 
preocupados con la disputa sobre la facticidad de los términos establecidos por la política razonable, sus demandas son automáticamente descalificadas como irracionales o poco realistas.

Precisamente debido a la primacía de una epistemología derivada de la noción de que el conocimiento es una relación entre un mundo real «ahí afuera» y sus representaciones, la «ciencia universal» juega el rol principal de árbitro en la política razonable, especialmente en el ejercicio del ordenamiento de la supuesta facticidad de las diferentes perspectivas ${ }^{10}$. La «ciencia universal» es un ensamble material semiótico, siempre cambiante y situado, en el cual el Estado, la ley y las prácticas de conocimiento que reclaman estatus científico se abigarran.

Semejante configuración hace razonable, moviliza y protege una equivalencia implícita entre la habilidad tecnológica y el aprehender la realidad tal como es. En términos muy simples: ¡sabemos que la ciencia conoce mejor porque podemos mandar un hombre a la Luna, y si quieres probar otra cosa deberás contratar los servicios de un científico natural o social! La «ciencia universal» no es, desde luego, el único criterio movilizado para ordenar facticidades competentes, pero tiende a ser el principal.

Más allá de descartar asuntos supuestamente irracionales o poco realistas, la política razonable plantea otro problema para el investigador que desee escapar de sus confines, y este consistiría en cómo dar cuenta de las diferencias en juego en conflictos como el descrito más arriba si uno desea que esas diversidades hagan una diferencia en la manera en que se da cuenta de ellas. El problema surge de una noción particular de política que se inspira en Jacques Rancière. Ranciére ha argumentado que los desacuerdos son a la vez fundacionales a la política y tienen la posibilidad de generar una «re-partición de lo político desde lo no político» (2011, p. 4). Sobre esta base, trato el concepto de «política» como un indicador de (i) diferencias que, mientras son potencialmente el terreno para desacuerdos, no están todavía definidas, y (ii) los varios caminos posibles por los cuales estas diferencias podrían (o podrían ser obligadas a) relacionarse entre ellas. La política razonable (o la «política usual») da por sentada su aplicabilidad universal y, más importante aún, asume que ha agotado las categorías de la diferencia (como cultura, clase, género, raza, sexualidad, etc.).

10 «Ciencia universal» refiere a la variedad de las prácticas de conocimiento que, afirmando seguir el ejemplo de las ciencias experimentales, pero en realidad distorsionando la naturaleza de las «verdades» que ellas producen, proclama conocer la realidad «tal como es» (ver Stengers, 2000). 
Alejándose de esta posición que presupone que los desacuerdos son fácilmente reconocibles, en mi «política como indicador», la naturaleza (y la existencia) misma de las diferencias puede ser lo que esté en juego y sea constitutivo de los desacuerdos. Por ejemplo, con respecto al conflicto sobre el caribú, algunas de las partes y de los investigadores podrían sostener que se trata de un conflicto «de clase» sobre el control de un recurso. En este caso, la diferencia / el desacuerdo es sobre quién es el propietario o controla un recurso. Quizá este sea el caso, y el conflicto estará relacionado con este desacuerdo. Pero, quizá hay otras partes e investigadores que ven el conflicto como un conflicto cultural que involucra conocimientos rivales. En este caso, la diferencia / el descuerdo se basará en quién entiende el problema «correctamente», y el conflicto en sí se desarrollará de modo diferente.

Dado que los conflictos se desarrollan diferentemente dependiendo del tipo de desacuerdo en juego, definir la naturaleza misma del desacuerdo - ies sobre el control de recursos o es sobre conocimientos rivales? - puede volverse el punto central del conflicto. Pero aquí puede haber otro giro. Digamos que otra parte afirma (como vamos a ver luego) que el conflicto entraña la protección de la red de relaciones que sostiene la vida de los innu, mientras que otras partes, a su vez, rechazan en su totalidad la idea de que semejante cosa pueda estar en juego: ellos están preocupados por la vida de los innu también. En este caso, lo que es operativo es la existencia misma del desacuerdo sobre lo que las partes difieren y están en desacuerdo.

Desde luego, todos estos desacuerdos (y otros que todavía no se revelaron) podrían estar operando simultáneamente. Por esta razón, es importante, en principio, permanecer tan agnóstico como sea posible sobre qué tipos de diferencia podrían constituir lo político en una situación dada ${ }^{11}$. Esta es en parte la razón por la cual el trabajo del investigador no puede ser separado del modo en que se desarrolla el desacuerdo. Que las diferencias en juego vayan a hacer una diferencia (y cómo la hagan) dependerá, como mínimo, de que tal diferencia sea articulada y hecha visible por, entre otros, los propios investigadores. Como he señalado, un análisis en términos de representación y perspectiva sobre el mundo «real» hace precisamente lo contrario: estipula desde el principio qué tipos de diferencias están en juego y, al hacerlo, termina jugando en favor de la política razonable y sus operaciones.

11 En este sentido, mi llamado a tratar ciertos conflictos como ontológicos en vez de como epistemológicos (Blaser 2013a, b) es, sobre todo, un llamado para, en principio, mantenerse agnóstico respecto del tipo de diferencia en juego en un desacuerdo dado. Diferencias ontológicas específicas son fundamentalmente proposiciones a posteriori. 
Las versiones material-semióticas de los Estudios de la Ciencia y la Tecnología (Science and Technology Studies - STS por su sigla en inglés), en las cuales el concepto de cosmopolítica está empíricamente basado, ofrecen un camino para abordar el impulso excluyente de la política razonable y la necesidad analítica de mantenerse agnóstico frente a las diferencias en juego en la política. Los materialistas-semióticos postulan la facticidad como el resultado siempre emergente de las prácticas de ensambles heterogéneos; solo a posteriori pueden estas prácticas ser purificadas y divididas entre hechos o sus representaciones (Haraway, 1988; Latour, 1999; Law, 2009).

Esta formulación ha sido influida grandemente por lo que se ve en aquellos sitios donde los académicos observan las prácticas científicas. Estos son lugares de construcción y de incertidumbre ontológica; sitios definidos por las preocupaciones o asuntos que son perfilados por la presencia de actantes que, si son capaces de articularse exitosamente, se vuelven «cuestiones de hecho» (matter of fact o MoF). Para decirlo brevemente, y tomando prestado uno de los ejemplos de Latour (1993b), antes de que todo fuera articulado exitosamente en el hecho «microbio», lo que tenemos es un «asunto o problema de interés» (matter of concern o MoC). Este es un asunto o una preocupación que (por decirlo de alguna manera) reúne un «ensamble» compuesto por Pasteur y sus colaboradores, por los higienistas sociales y sus detractores, por la levadura, etc. La trayectoria de una cosa desde $\mathrm{MoC}$ a MoF implica un proceso de singularización de la multiplicidad y la beligerancia de la asamblea/ensamble. Desde luego esta trayectoria es reversible: un hecho estabilizado puede volver nuevamente a ser un problema, haciendo entonces visible la presencia de la totalidad del ensamble que lo constituye. Es importante tener en cuenta, de todos modos, que aquí estamos hablando de visibilidad. Incluso un hecho, una entidad estabilizada, es siempre una multiplicidad. Una multiplicidad no implica muchas unidades, sino, en las palabras de Annemarie Mol (2002) y Marilyn Strathern (2004), más de uno pero menos que varios.

Latour (2004a) ha argumentado que, en contraste con una forma de crítica que gira alrededor de (lo que podríamos llamar) «facticidad realista», el punto de los análisis materialistas-semióticos que muestran cómo las cosas son ensambladas o constituidas no es rechazar su realidad, sino mostrar (y, mediante el análisis, participar en) cómo se vuelven reales por medio del entretejido de múltiples preocupaciones; esto, asimismo, involucra cómo las cosas se desrealizan cuando sus ensambles se dispersan o se tornan polémicos. Así, donde la política razonable significa una política de perspectivas jerárquicamente estratificadas en 
relación con un mundo factual ya existente, el materialismo-semiótico permiten una política de «hacer mundos», es decir, una política preocupada por los procesos mediante los cuales un mundo se real-iza, es decir deviene existente. Esta formulación desactiva la premisa básica de la política razonable —un mundo factual ya existente - y su capacidad de adjudicar quién y qué puede ser parte de lo político en términos de su adherencia a esta versión particular de facticidad.

Como expresa Latour:

De ahora en adelante, la política es algo enteramente diferente [...] es la construcción del cosmos en el que todos vivimos, la progresiva composición del mundo común [...] De ahí el excelente nombre que Isabelle Stengers ha propuesto dar a toda la empresa, el de cosmopolítica (2007, p. 813).

En la versión latouriana de cosmopolítica, el único requerimiento para que las cosas sean legítimamente parte de la tarea de construir un mundo común es que sean un asunto de interés, problema (un MoC) que atrae un público, un ensamble o conjunto (no solo de humanos, por supuesto). Pero, en la formulación de Latour, esta equivalencia bastante rápida entre cosmopolítica y la composición progresiva de un mundo común parece inspirarse principalmente en lo que sucede con las controversias científicas; en estos casos la multiplicidad en juego en un MoC que atrae una asamblea ya es visible y legible, por así decirlo. Siguiendo más de cerca la versión de cosmopolítica de Stengers y su insistencia en no perder de vista a las «víctimas» (aquellos sin poder para representarse a sí mismos o quienes no desean formar parte en la composición del mundo común porque «hay algo más importante que el problema propuesto»), María Puig de la Bellacasa (2011) ha propuesto la escenificación de «cuestiones o asuntos de cuidado». Central a los asuntos de cuidado es el reconocimiento de que en mundos profundamente estratificados «las preocupaciones invisibilizadas no devienen visibles por seguir las preocupaciones articuladas y ensambladas que componen una cosa, ni la generación de atención ocurre por contar los participantes presentes en un asunto» (de la Bellacasa, 2011, p. 94). En este contexto, las nociones feministas de un punto de vista crítico se vuelven cruciales para hacer visibles asuntos «ausentes». En contraste con la crítica deconstructiva, que usaría las ausencias como un arma para atacar la «veracidad» del conjunto constitutivo de un $\mathrm{MoC}$, un punto de vista crítico trae a colación las ausencias para fomentar nuevos lazos y cuidados hacia los participantes y las preocupaciones hasta ahora ausentes. Un punto de vista crítico contribuye a «cortar» la forma de un asunto de otra manera. Esta es una poderosa corrección a la formulación de Latour, una corrección que inspira mi siguiente análisis. 


\section{Cuidando atîku / caribú: más que uno pero menos que varios}

Desde 2009 he estado participando en un proyecto de investigación colaborativo con un grupo del pueblo innu de Labrador. Las comunidades innu están situadas en Labrador y en Quebec y están sujetas a dichas jurisdicciones provinciales (ver mapa).

\section{Comunidades innu}

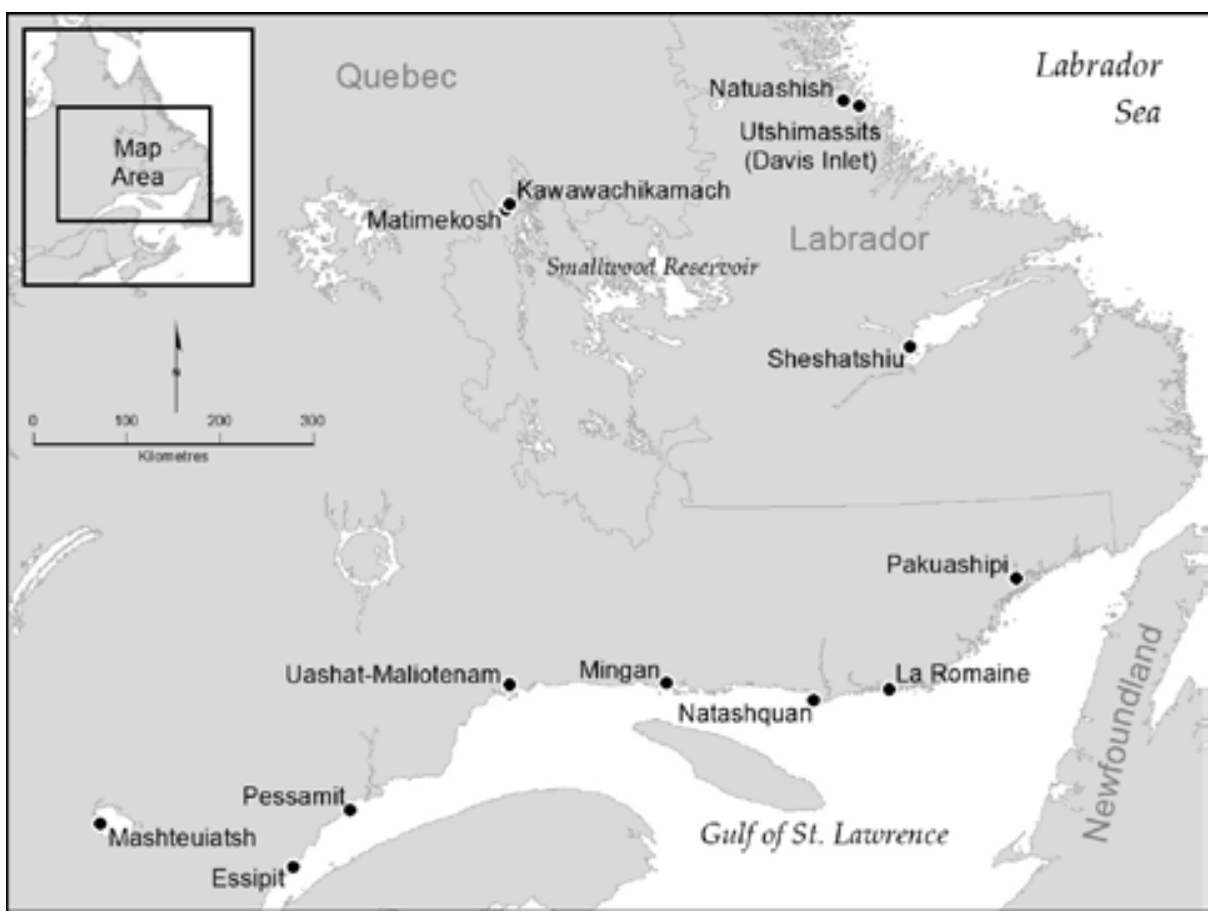

Mapa de Damián Castro, utilizado con autorización.

El proyecto que describo aquí comenzó a tomar forma cuando conocí a un grupo de ancianos y cazadores innu de Labrador de una organización sin fines de lucro llamada Tshikapisk ${ }^{12}$. Este grupo estaba preocupado por el vertiginoso

12 La organización «fue creada en 1997 por un grupo de Innu preocupados con las disruptivas consecuencias que el cambio repentino de una vida basada en el territorio a una basada en asentamientos permanentes trajo para los Innu» (de su website http://www.tshikapisk.ca/ home/). 
descenso de atîku, que para ese momento había comenzado a volverse obvio. Como mencioné anteriormente, para muchos cazadores y ancianos, esta caída de la población era un síntoma de la deteriorada relación entre los innu y Kanipinikassikueu, el «señor» de los atîku. La preocupación de los miembros de Tshikapisk se vio agravada por la propuesta que comenzaba a ser promovida por algunos biólogos y por un creciente segmento del público de Labrador, de que cuidar la menguante manada de caribúes en el contexto de cambios en el terreno, aumento de temperatura y extracción de recursos demandaba que toda caza fuera detenida ${ }^{13}$. Atendiendo a las prácticas de cuidado que la relación con Kanipinikassikueu provoca en los cazadores innu, puso en evidencia para nosotros que los atîku eran muy diferentes de lo que los biólogos y los eurocanadienses llamarían una «especie animal».

De acuerdo con un atanukan (historias que narran el origen de las cosas), un hombre innu cuyo grupo estaba hambriento fue a vivir con los atîku, se casó con la hija del líder del rebaño, se transformó en atîku y finalmente se volvió Kanipinikassikueu. Desde entonces, Kanipinikassikueu persuade a los atîku de que se entreguen a los innu, así estos pueden sobrevivir. Sin embargo, esta generosidad no está garantizada. Como muchas etnografías han apuntado, atîku tiene voluntad propia, por lo tanto la "caza» (nataun) no se trata principalmente de engañar a los animales para «matarlos» (nipaieu), sino de atraer a estos seres con total volición y a su líder para que sean generosos con sus cuerpos. Esto se logra mediante prácticas que muestran respeto y reconocimiento por esos actos altruistas. Entre estas prácticas hay protocolos para disponer de los huesos de los atîku que han sido cazados (de los cuales nuevos especímenes se regenerarán), el mandato de no desperdiciar ninguna parte de sus cuerpos, y el requerimiento de que la carne debe ser generosamente compartida entre la gente. Otras prescripciones, como mantener a Kanipinikassikueu en la mente contando historias, cantando, tocando el tambor y celebrando una comida ceremonial (mokoshan), sirven para recibir su bendición para el bienestar general (ver Armitage, 1992; Heriksen, 1973, 2008).

Cazar (nataun) es, por lo tanto, un conjunto de prácticas de «cuidado», que aseguran la continua realización de la generosidad y el respeto al interior de este colectivo de humanos y no humanos. Con todo, la caza es también un momento que es muy indicativo de cuán saludables están las relaciones dentro de este colectivo: una disminución de la frecuencia en que atîku se entrega a los cazadores

13 La prohibición de cazar no sería instaurada hasta cuatro años más tarde, en 2013. 
es un síntoma de que Kanipinikassikueu está enojado. Reportando sobre una circunstancia semejante, Henriksen (1977, p. 7) escribió:

La búsqueda de las razones para explicar el enfado de Katipinimitautsh equivale a un autoexamen para encontrar posibles faltas en la relación espiritual y moral [de los innu] con la naturaleza, entre ellos, y entre ellos y los animales [...] Puede ser algo muy serio: Alguien puede haber violado las reglas de compartir, o alguien puede haber sido descuidado al manejar la médula de los huesos largos del caribú.

La mayoría de los ancianos y cazadores con que mis colegas y yo hablamos durante el proyecto entendían la disminución de la presencia de atîku en esta clave. Ellos señalaban que la falta de respeto por el atîku era rampante entre las generaciones más jóvenes. Mencionaron restos de atîku siendo llevados por perros, gente vendiendo carne, y una falta de interés general entre los jóvenes sobre la vida en el campo. Para la mayoría de ellos las consecuencias son obvias no solo en la disminución de los rebaños sino también en las epidemias de adicción, suicidio y diabetes que han afectado a las generaciones más jóvenes de innu durante los últimos veinte años (ver Samson, 2003). Durante un taller que mantuvimos en 2010, el anciano Ponas Nuke expresó el problema así: «Sin atîku no somos nada. Si no estamos afuera en el campo, cazando, llegará el día que Kanipinikassikueu no nos conocerá, él preguntará ¿quiénes sois vosotros? Y si nosotros no tenemos su bendición, las cosas se pondrán peor» ${ }^{14}$.

En 2009, los gobiernos de Terranova y Quebec acordaron comisionar un estudio para evaluar el estatus de la manada del río George (George River Herd - GRH). Para esto, nuevos collares de radiofrecuencia fueron colocados en varios animales de la manada para poder ubicarlos con helicópteros durante los meses de verano. Este conteo aéreo, corregido de acuerdo con criterios biométricos prestablecidos (ver Rivest, Couturier and Crepeau, 1998), proveyó la base para estimar la población. Esta evaluación fue luego combinada con estudios previos, así también como con otros factores que es sabido que afectan los ciclos poblacionales, con el fin de proponer una serie de medidas para la sostenibilidad de la manada que fueron presentadas a las partes interesadas locales (Newfoundland and Labrador Wildlife, 2010). Estas medidas se basaban en la conclusión de que la caza era «ahora significante y acumulativa a la mortalidad natural». En otras

14 «Without atîku we are nothing. If we are not in the land, hunting, the day will come when Kanipinikassikueu will not know us, it will ask: "Who are you, people?". And if we do not have its blessing, things will get worse»». 
palabras, el cuidado de la población de caribú dependería de las restricciones en la caza. En la presentación hecha para todas las partes interesadas locales se dejó claro también que, desde la perspectiva del gobierno, los esfuerzos de conservación tienen precedencia sobre los derechos aborígenes de cazar. Desde esa reunión, los no aborígenes comenzaron a presionar al gobierno para que aplicara una prohibición total de cazar la especie.

El estudio y las medidas propuestas se basaban en una serie de presunciones sobre el caribú que son estándares en la biología y el manejo de animales silvestres. Por lo tanto, el estudio fue conducido sobre una manada específica de caribú, demarcado de acuerdo con su movilidad territorial y variabilidad genética. Asimismo, el estudio se basó en la suposición de que el caribú, manejado por su instinto, se comporta de un modo predecible. Por ejemplo, durante el verano, los caribúes se juntan en grupos compactos para protegerse de los insectos chupasangre, por lo tanto, siguiendo a los animales con collares de radio frecuencia los investigadores, podría acceder a grupos y enumerar a los animales. En una etnografía reciente, Damián Castro, uno de nuestros asociados al proyecto, reporta un incidente que muestra cómo estos presupuestos sobre el caribú pueden encontrarse en marcado contraste con las visiones sobre atîku sostenidas por los cazadores innu.

Un día, mientras estaba en la oficina de la Nación Innu, un cazador muy experimentado que había sido recientemente acusado de caza ilegal vino a la oficina donde yo trabajaba y me dijo «encontraron un collar de la manada de Red Wine [una manada protegida por más de quince años] cerca del lago Kamistastin; Mira, atîku quiere ir allí». Lago Kamistastin se encuentra a unos 400 kilómetros al norte de Sheshatshiu, muy lejos del alcance de la manada de Red Wine, y justo en el área de migración de la manada del río George. Esta información, como él y otros innu argumentan, demuestra que la manada del bosque de Red Wine y la manada migratoria del río George se entremezclan. Por lo tanto, no tiene sentido declarar la caza ilegal sobre la base de la suposición sostenida por los científicos del gobierno de que los rebaños son diferentes: para los innu solo hay atîku. Además, las palabras de este cazador indirectamente indican diferencias en cómo se usa la información del collar. El gobierno la usa para obtener la información que los científicos necesitan para aprender sobre el comportamiento del caribú, como por ejemplo su paradero, mientras que los innu usan esta información para saber lo que atîku quiere. En otras palabras, mientras el gobierno administra los collares para satisfacer su voluntad de saber, los innu lo usan para conocer la voluntad de atîku. Al igual que los seres humanos, atîku tiene voluntad (Castro, 2015). 
Las diferencias entre atîku y caribú no significan que no haya conexiones entre ellos. Por ejemplo, las señales de GPS enviadas por los collares para monitorear los movimientos y la demografía del caribú fueron, hasta 2010, transferidas por el Ministerio de Medio Ambiente de Quebec a mapas disponibles online. Consultando esos mapas, los cazadores innu podían identificar las áreas donde era posible encontrar atîku. Esta información era extremadamente importante para los cazadores que querían mantener su relación con atîku pero que, desde la década de 1970, han encontrado su tiempo cada vez más restringido por sus obligaciones de trabajo en los asentamientos permanentes. De manera análoga, los biólogos y los administradores de la fauna silvestre a menudo han dependido del apoyo provisto por los cazadores innu para colocar collares y hacer observaciones sobre el caribú. Aun así, a pesar de sus mutuos enredos, atîku y caribú siguen siendo diferentes. La manera más obvia en que esta diferencia se manifiesta es que el primero es una persona no humana que tiene voluntad, mientras que el último es un animal manejado por instintos.

¿Pero cómo comprender esas diferencias sin recurrir a nociones de diferentes perspectivas sobre una única «cosa» y así caer en la trampa impuesta por la política razonable? Los recursos conceptuales del materialismo-semiótico discutidos en la sección anterior ofrecen un camino. Atîku / caribú es múltiple; es más que uno pero menos que varios. Sin embargo, la multiplicidad en juego aquí no es exactamente la misma que la concebida por Latour o Mol; esto es, la idea de que una «cosa» es siempre el resultado estabilizado de una ensamble o conjunto de actantes que potencialmente podría devenir en controversias. En este caso, el significado de multiplicidad como «más que uno pero menos que varios» podría ser mejor evocado por esta figura.

Aquí tenemos un pájaro mirando a la izquierda y un conejo mirando a la derecha: más que uno pero menos que dos. Es un pájaro y un conejo, y aun así, no son dos unidades, y mientras los trazados se superponen no es solo un dibujo. Si imaginamos que los cuerpos del pájaro y del conejo no se superponen tan claramente como sus cabezas, podemos comprender la idea de que podría haber una co-ocurrencia parcial de las entidades, pero la diferencia no se cancela. De manera similar, los ensambles material-semióticos de los cuales el más que uno pero menos que varios atîku / caribú emerge co-ocurren parcialmente (más evidentemente en la presencia corporal) - y en algunos puntos esta co-ocurrencia puede incluso ser mutuamente facilitada (como ocurre con los collares de radiofrecuencia) - , pero se mantienen distintos. Atîku emerge de un ensamble que contiene a atanukan, cazadores, el compartir carne, la generosidad, un espíritu 
guardián, etc.; caribú emerge de un ensamble que incluye a la disciplina de la biología, a los administradores de fauna silvestre, modelos predictivos, cálculos para balancear preocupaciones ambientales y económicas, etc. La dificultad para convertir este tipo de multiplicidad en una cosa singular, por ejemplo, mediante un acuerdo de cómo enfrentar la disminución de su número, debería hacer de atîku / caribú un asunto de interés, un problema (MoC). Pero este no es siempre el caso.

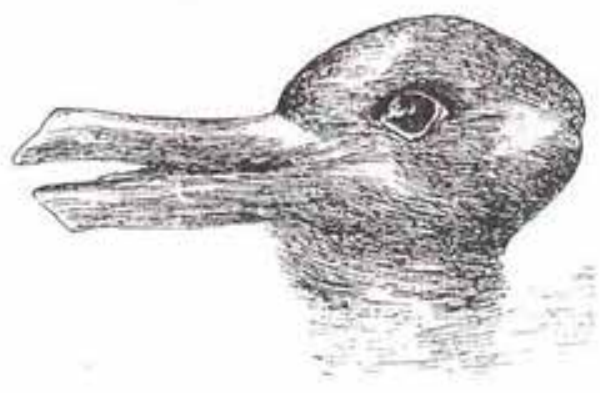

\section{ATÎKU / CARIBÚ: LA EXTRAÑA} TRAYECTORIA DE UN ASUNTO

Como veremos, el (más que uno pero menos que varios) atîku / caribú se ha vuelto ahora un problema en Labrador. Pero no lo era antes, y aun así, tampoco era exactamente un asunto de hecho, un MoF. La extraña trayectoria de este asunto plantea interesantes preguntas sobre cómo la especificidad de la multiplicidad revelada en este caso podría afectar las políticas de hacer mundos. Para hacer esta trayectoria visible, tengo que traer a cuenta la controversia generada alrededor de la propuesta del proyecto de Lower Churchill, un proyecto hidroeléctrico de 6 billones de dólares canadienses, y su relación con la compleja dinámica del reclamo territorial de los innu de Labrador.

En Canadá, los «reclamos territoriales» son dirigidos a cambiar derechos difusos que un pueblo indígena puede tener sobre una extensión grande de territorio por derechos y privilegios claramente definidos sobre áreas y recursos más restringidos. Los derechos indígenas difusos sobre grandes territorios no previenen a los gobiernos provinciales de dar permisos a las corporaciones para explotar sus recursos naturales. Por lo tanto, aunque pagando el precio de «extinguir» sus derechos sobre la totalidad del territorio, la resolución de una reivindicación territorial implica certeza legal, un sustancial flujo de dinero por un corto plazo, y puestos de trabajo para las comunidades dentro de los proyectos de explotación de los recursos locales.

Dadas estas condiciones, las reivindicaciones territoriales a menudo producen divisiones al interior de las comunidades (ver Samson y Cassel, 2013). El caso de la reivindicación de tierra de los innu de Labrador no es diferente. La posibilidad de resolver esta reivindicación se volvió de alguna manera condicional a la 
aceptación de los innu de la construcción del Proyecto del Lower Churchill, que era (y continúa siendo) un asunto extremadamente polémico en las comunidades. Ancianos y gente que mantiene conexiones fuertes con el territorio (incluyendo, desde luego, atîku) rechazaba el proyecto, en oposición a un grupo de líderes inclinados a firmar el acuerdo.

A pesar de estos desacuerdos, los pasos hacia la ejecución del proyecto continuaron, incluyendo un Estudio de Impacto Ambiental (Environmental Impact Assessment - EIA), que es obligatorio por ley y requiere un proceso de consulta con múltiples interesados. Durante el EIA, un review panel (panel de revisión) evalúa los efectos biofísicos, sociales, económicos y culturales del proyecto y las medidas de mitigación que serán necesarias para compensarlos. El proceso de evaluación genera un reporte final que se presenta al ministro de Medio Ambiente federal para su aprobación final. El estudio del proyecto Lower Churchill comenzó en enero de 2009 y estuvo plagado de controversias entre biólogos y otros expertos en el manejo de fauna silvestre, tanto gubernamentales como no gubernamentales, que discrepaban en muchos puntos, incluyendo el criterio que cada uno usó para estimar impactos, la selección de especies indicadoras, los métodos de investigación y cuestiones semejantes ${ }^{15}$.

Las preocupaciones innu se incluyeron en el proceso de evaluación mediante un informe sobre el uso de la tierra, encargado por la nación innu y presentado al panel de revisión, y por reuniones de consulta en las comunidades organizadas por el mismo panel. El autor del informe de uso de la tierra enfatizó que la información incluida en él tenía una limitación crucial: «El reporte no podía transmitir cabalmente el profundo significado y afecto que muchos innu sienten por la tierra y las entidades vivientes que residen en el Área de Estudio» (Armittage, 2010, p. 16). Sin embargo, algo de ese significado y afecto surgió en la reunión de consulta pública organizada por el panel revisor. Directamente en inglés, o por medio de un traductor, muchos innu hicieron emotivas presentaciones sobre las consecuencias de la presa: «Cuando pienso sobre ello, es como que destrozas $[\ldots]$ no solo destrozas la tierra y los animales, también destrozas nuestras vidas, la vida de los innu» (Joint Review Panel - JRP, 2011, p. 149) ${ }^{16}$.

15 «Lower Churchill Hydroelectric Generation Project Joint Review Panel», Volume 13. Ver: http://www.ceaa.gc.ca/050/documents/48784/48784E.pdf. El Sierra Club Canada denunció que el panel revisor al final no evaluó los efectos ambientales sobre la manada de caribú del Rio George.

16 «When I think about it, it's like you destroy [...] not only you destroy the land or the animals, you also destroy our lives - the life of the Innu». 
Además de estas evaluaciones generales, ponentes innu mostraban preocupaciones específicas sobre el impacto del proyecto en los patrones de migración y en la habilidad de moverse en el paisaje cambiado de atîku. Algunos participantes se preguntaron explícitamente sobre las reacciones que poderosos no humanos podían tener a raíz de esto. Por ejemplo, uno de los ancianos que participaba en la consulta dijo:

No me gusta la idea de construir una represa en las cataratas del Muskrat. Por lo que sé de Muskrat Falls, hay un agujero en alguna parte de las cataratas. Probablemente un espíritu en el mundo de los espíritus usó esa cascada por una razón; quienquiera que sea vive en esa colina. Probablemente el espíritu que vive en la montaña destruirá la represa, de alguna manera [...] Creo que los seres animales que viven en esa montaña destruirán la represa (JRP, 2011, pp. 71-72) ${ }^{17}$.

No todos los innu dieron el mismo peso a estas preocupaciones. Un sector del liderazgo enfatizó los beneficios del proyecto y presentó las preocupaciones de los ancianos y los cazadores como un anhelo romántico y poco realista por un modo de vida que ya no es posible (JRP, 2011, pp. 103-123). Las generaciones más jóvenes, por lo tanto, se encontraron en el dilema de calibrar las preocupaciones de los ancianos y los cazadores frente a las promesas de empleo y la perspectiva de terminar con el limbo legal en el que viven los innu de Labrador al no tener resuelta la demanda de tierra. En cualquier caso, cuando las preocupaciones de los ancianos y los cazadores fueron transferidas al informe preparado por el panel revisor, todas las menciones a no humanos como algo más que animales fueron traducidas como «cultura» y tratadas como un asunto de «espiritualidad» en la sección de «Heritage and Culture» («Patrimonio y Cultura») (JRPR, 2011, p. 184). En contraste, y con la excepción de hacer notar el «valor moral» del caribú, los contenidos del «Traditional Environmental Knowledge» (conocimiento medioambiental tradicional) que fueron susceptibles de corroboración científica (es decir, los patrones de migración, los comportamientos estacionales y cosas semejantes) fueron incluidos en la sección titulada «Impacts to Terrestrial Environment and Wildlife» («Impactos en el Medio Ambiente Terrestre y en la Fauna Silvestre») (JRPR, 2011, pp. 114-117).

17 I don't like the idea of damming the Muskrat Falls. What I know about Muskrat Falls, there's a hole in the falls somewhere. Probably the spirit in the spirit world used that waterfall for a reason, whoever being lives in that hill. Probably the spirit that lives in the mountain probably will destroy the dam itself, somehow [...] I think that the animal beings who live in that mountain will destroy the dam. 
En resumen, en el informe, las preocupaciones innu fueron separadas (e implícitamente clasificadas) de acuerdo con un criterio de «sentido común» que distingue la información medioambiental confiable de las creencias culturales. Después de que el panel terminara las consultas y entregara su informe al ministro de medio ambiente federal, el gobierno de Canadá determinó que los importantes beneficios energéticos, económicos, socioeconómicos y ambientales esperados superaban los «significativos efectos ambientales adversos» del proyecto que se habían identificado en el Informe del Grupo Especial (Government of Canada, 2012, p. 6).

Organizaciones medioambientales opositoras al proyecto encontraron en la posición de los ancianos y cazadores innu un punto de resonancia, y por lo tanto, en algunos de sus comunicados de prensa enfatizaron, entre otras cosas, los valores «espirituales» aborígenes que estaban en juego ${ }^{18}$. Sin embargo, esta coincidencia solo llegó hasta un punto. La indignación generada por la caza de protesta organizada por los innu de Quebec es un ejemplo de ello. Estas comunidades organizaron una caza en una manada protegida en Labrador para señalar que la provincia de Terranova y Labrador debería incluirlos a ellos y no solo a los innu de Labrador en las discusiones sobre el proyecto de Lower Churchill ${ }^{19}$. Desde la perspectiva de los innu de Quebec, no había contradicción en afirmar su cuidado por el atîku y cazarlos para imponer la noción de que, incluso cuando los límites provinciales del estado colonial dijeran lo contrario, ellos eran interlocutores relevantes sobre el destino del territorio. El tono de las respuestas a esta acción fue mayormente análogo a lo que un lector comentó en el sitio de noticias de CBC:

Toda esta situación me vuela la cabeza. Realmente no puedo entender su mentalidad. ¿Qué pasó con todo lo que tenía espíritu y ser uno con la tierra? Están violando la tierra. Apuesto a que sus antepasados están removiéndose en sus tumbas. Deben ser arrestados, claro y simple ${ }^{20}$.

Muchos eurocanadienses vieron la caza como una prueba de que las afirmaciones respecto de las conexiones espirituales con atîku eran solamente una artimaña que los «aborígenes modernizados» estaban usando para extraer beneficios del

\footnotetext{
18 Ver: http://damsandalternatives.blogspot.ca/2010/12/first-nations-rally-against-lower.html

19 Ver: http://www.cbc.ca/news/canada/newfoundland-labrador/story/2010/02/21/nl-hunt-protest. html

20 This whole situation just blows my mind. I really can't wrap my head around their mentality. What happened to everything having a spirit and being one with the land? They are raping the land. I bet their ancestors are rolling in their graves. They should be arrested, plain and simple.
} 
proyecto propuesto. En otras palabras, si la conexión espiritual con el caribú no se traducía en lo que los eurocanadienses reconocerían como «cuidado», luego no había tal conexión.

Separando las preocupaciones innu en aceptables e inaceptables, o entre aquellas que pueden mantenerse junto con el conocimiento basado en la ciencia y aquellas que son «solo» culturales, podemos ver el trabajo de la política razonable. Pero en términos de políticas de hacer mundos, o de MoC, podemos también ver que esta división crea también otra distinción. Por un lado, algunas preocupaciones pueden componer un «asunto»y, por lo tanto, aspirar a volverse parte de lo que puede finalmente volverse un MoF, una parte del mundo común. Por otro lado, otras preocupaciones simplemente no constituyen un asunto. Y esto, desde luego, señala una asimetría.

Siendo funcional a una forma de cálculo más o menos formalizada que racionaliza, entre otras prácticas, las regulaciones de caza y masivas transformaciones del paisaje, el caribú (y en términos más generales «los animales») sí afectan la composición de atîku. De modo más inmediato, esto ocurre mediante la imposición de cuotas de caza, la demarcación de áreas protegidas y la alteración de las rutas de migración de la manada que fuerza una recomposición de la caza y la distribución de carne, prácticas que parcialmente constituyen atîku. En contraste, la presencia de atîku no ha afectado la forma en la que el caribú ha sido compuesto como MoC durante la controversia de Lower Churchill, o más generalmente como un cuasi MoF. En otras palabras, las preocupaciones de los innu por atîku no han constituido un «asunto», al menos no hasta recientemente.

Después de que el panel de revisión medioambiental llevara a cabo sus consultas, las comunidades innu tuvieron una votación de ratificación del acuerdo de Tshash Petapen (Nuevo Amanecer) que la nación innu y el gobierno provincial habían estado negociando. El acuerdo contiene tres partes: un acuerdo preliminar de tierras (Land claims Agreement-in-Principle) que estipula los derechos que los innu conservarían en un territorio especifico, una compensación económica por el proyecto Upper Churchill que fue construido a finales de la década de 1960 sin consideración por los derechos innu, y el Acuerdo de Impactos y Beneficios por el propuesto proyecto Lower Churchill. En general, el acuerdo marca los términos generales bajo los cuales el reclamo territorial innu sería acordado y la construcción del proyecto Lower Churchill podría proceder. Sin embargo, el acuerdo general y sus tres componentes tenían que ser ratificados en forma separada por las comunidades innu. La votación ratificatoria del acuerdo general tuvo lugar en junio de 2011. Con el apoyo mayoritario de las generaciones más 
jóvenes de innu, el acuerdo fue ratificado ${ }^{21}$. Esto permitió al gobierno de Terranova centrarse en otros aspectos cruciales del proyecto, como la ingeniería financiera ${ }^{22}$.

Al final del otoño boreal de 2012, cuando los rumores acerca de que el gobierno de Terranova iba a tomar medidas drásticas con respecto a la crisis del caribú comenzaron a expandirse, la nación innu convocó a una reunión comunitaria para discutir qué harían en caso de que se impusiera una prohibición. Mucha de la gente que había votado en favor del acuerdo de Tshash Petapen dijo que una prohibición en la caza de atîku sería una violación del Acuerdo Preliminar de Tierras (Land Claim Agreement-in-Principle - AIP). Por lo tanto, ellos estarían ahora del lado de quienes se habían opuesto al proyecto Lower Churchill desde el principio por sus potenciales efectos en atîku, y en términos más generales, en el territorio.

Las consecuencias de este cambio se vuelven claras cuando consideramos que el AIP todavía tiene que ser ratificado por votación en las comunidades innu y, según el Tshash Petapen, los tres acuerdos contenidos en este se volverán nulos si cualquiera de sus componentes no es ratificado por alguna de las partes. Cuando los resultados de la reunión comunitaria fueron filtrados al público, un periodista dio voz a un entendimiento silenciado: habría que ver si el gobierno de Terranova sacrificaría un proyecto hidroeléctrico de 6 billones de dólares para que los innu dejaran de $\operatorname{cazar}^{23}$. En síntesis: atîku se transformó en un MoC (asunto de cuidado) ineludible.

Contrariamente a la controversia sobre el proyecto Lower Churchill durante el proceso de Evaluación del Impacto Ambiental, esta vez la situación es tal que las preocupaciones por el caribú no pueden ser calmadas fácilmente sin atender las preocupaciones por atîku. Sin embargo, esta no es la típica trayectoria de una «cosa» (por ejemplo, caribú), que se transforma de ser un MoF a ser un MoC. Más bien esto incluye la sorpresiva visibilidad e inevitabilidad de participantes que estaban alli durante todo el tiempo. Aun así, estos participantes no tienen lugar en el proceso de ensamble en el que caribú fue puesto en escena como MoC con la posibilidad de ser articulado como un MoF. Esto apunta a la problemática particular que la co-presencia de diferentes ensambles (conectados asimétrica y parcialmente) presenta a la cosmopolítica orientada al mundo común.

21 Ver http://www.cbc.ca/news/canada/newfoundland-labrador/story/2011/07/04/nl-riche-innunew-dawn-704.html. Acceso agosto 19, 2013.

22 Ver http://www.releases.gov.nl.ca/releases/2011/exec/1118n11.htm. Acceso agosto 19, 2013.

23 Ver http://www.thetelegram.com/Opinion/Columns/2013-02-09/article-3173526/Pokingan-Innu-bear-with-a-caribú-stick/1. Acceso agosto 19, 2013. 


\section{CONCLUSIÓN: MUNDO COMÚN Y MUNDOS NO COMUNES}

Aunque mayormente ha sido tratado como una entidad discreta que puede ser entendida desde diferentes perspectivas, en Labrador el caribú nunca ha sido solo un caribú, una entidad única. Aun así, la multiplicidad de los ensambles que pueden ser singularizados en un caribú más o menos estabilizado (por ejemplo, en debates sobre el criterio apropiado para evaluar los impactos de un proyecto de desarrollo en las manadas) no es la misma que aquella en donde atîku puede ser estabilizado (por ejemplo, en debates sobre los protocolos apropiados para asegurar la generosidad del señor del atîku). Lo que está en juego no es solo la multiplicidad ontológica, sino también múltiples formas de hacer mundos. Esto provoca algunas preguntas fundamentales: ¿cómo una preocupación en una forma de hacer mundo se puede volver una preocupación en otra forma de hacer mundo? ¿Qué es lo que se requiere para que un asunto de interés dentro de una forma de hacer mundo sea registrado como tal dentro de otra forma, cuando ambas están conectadas asimétricamente? Las preguntas son empíricas y también tienen consecuencias prácticas sobre nuestros roles como investigadores y co-compositores de asuntos de preocupacion (MoC). El término 'asuntos de cuidado' propuesto por De la Bellacasa (2011) para hacer presentes preocupaciones ausentes es crucial, pero nuestro caso muestra que, aunque necesaria, esta movida no es suficiente. Después de todo, atîku produjo «cuidado» (es decir, fue hecho visible como una preocupación) durante el Estudio de Impacto Medioambiental, pero aun así no calificaba como un asunto que mereciera atención hasta que puso en riesgo un proyecto de desarrollo multibillionario. E incluso así, es dudable que atîku se haya vuelto un asunto de preocupacion en el sentido concebido por una cosmopolítica orientada a la composición de un mundo común, esto es, como una preocupación que pueda aspirar a participar en la composición de un asunto de hecho (MoF).

A veces, diferentes formas de hacer mundos pueden coexistir - posibilitándose mutuamente o sin prestarse atención- pero en otras ocasiones se interrumpen. Al no ser reducible a los términos del otro, cuando y donde las diferentes formas de hacer mundos se interrumpen entre sí, la multiplicidad en juego no podría ser susceptible a la clase de singularización que la constitución del mundo común de Latour parece requerir. Recordemos que, para Latour, la composición del mundo común se modela siguiendo la trayectoria que un ensamble podría seguir al pasar de ser un asunto de preocupacion (una multiplicidad mal articulada de actantes al borde de la dispersión) a convertirse en un asunto de hecho (una reunión de los actantes que está tan bien articulada que se estabiliza como una unidad, una 
«cosa» en singular). En este sentido, el comentario citado anteriormente, llamando a la Policía a detener a los cazadores innu de Quebec y la inminente amenaza de detenciones en virtud de la prohibición actual, son muy reveladoras. En efecto, si tomamos estas amenazas como parte del procedimiento utilizado para articular y estabilizar el caribú como una «cosa» (es decir, que sea un 'asunto de hecho') a pesar de las perturbaciones producidas por atîku, se podría reflexionar sobre la consecuencia de enactuar una cosmopolítica como la composición del mundo común cuando de la multiplicidad en juego no es pasible de ser singularizada.

Latour (2004b, p. 124) respondería: «De estas entidades excluidas no podemos decir nada excepto que se exteriorizan o externalizan: se ha tomado una decisión colectiva explícita para no tomarlas en cuenta; deben considerarse insignificantes $\rangle^{24}$. Por lo tanto, permanecen fuera del mundo común que está siendo compuesto. Sin embargo, lo que el caso atîku / caribú nos muestra es que el hacer el mundo común no siempre produce solo una «externalidad»: a veces interrumpe y destruye otras maneras de hacer mundos, pues cuidar al caribú de cierta manera pone en peligro la existencia de atîku. En resumen, entonces, en lugar de algo totalmente diferente, y en la medida en que las entidades que se mantienen fuera del mundo común se vuelven insignificantes, una cosmopolítica orientada al mundo común podría terminar pareciéndose a una política razonable reconfigurada.

Esto es algo de lo que Stengers parece muy consciente, de ahí su insistencia en que la composición del mundo común solo debe proceder en presencia de las «víctimas», no porque estas deban de estar de acuerdo, sino más bien porque los que han acordado avanzar en los términos del mundo común «tienen que saber que nada podrá borrar la deuda que vincula su eventual decisión con sus víctimas» (Stengers, 2014, p. 39). Y, sin embargo, mientras Stengers hace que sea más difícil y más lento de lo que Latour parece buscar, el mundo común «debe ser compuesto».

¿Pero debe serlo necesariamente? ¿Puede la cosmopolítica ofrecer únicamente la composición más lenta posible del mundo común? ¿O hay otra cosmopolítica posible? Indicios para una respuesta aparecen en algunos eventos que tuvieron lugar poco antes y después de que se aprobara la prohibición de la caza.

En respuesta al problema de la disminución de la presencia de atîku, como es definida por los ancianos y los cazadores innu, nuestro equipo de investigación

24 «Of these excluded entities we cannot yet say anything except that they are exteriorized or externalized: an explicit collective decision has been made not to take them into account; they are to be viewed as insignificant». 
había estado discutiendo algunas intervenciones. Una de ellas era la conversión de los protocolos de caza del atîku en políticas que los innu podrían hacer cumplir. Cuando los rumores de una prohibición de la caza se multiplicaron, miembros del equipo de investigación y personal de la nación innu llevamos a cabo conversaciones informales con el personal local de la división de vida silvestre del gobierno provincial. Nuestra intención era evitar una prohibición de la caza.

Sostuvimos que, dado que requiere una inversión considerable de tiempo y trabajo, si los innu seguían el protocolo adecuado para tratar atîku probablemente se reduciría el número de individuos cazados. Parte del argumento que hicimos a los agentes de vida silvestre incluyó la mención a una serie de aspectos de la situación que eran evidentes para ellos, incluso si eran reacios a hablar de ellos abiertamente. En primer lugar, era poco probable que una prohibición basada en la afirmación de que cesar la caza solucionaría la «crisis del caribú» fuese cumplida por los innu. En segundo lugar, la amenaza de procesamiento nunca ha disuadido a los innu de cazar, y la capacidad real de los agentes de vida silvestre para hacer cumplir la prohibición en el terreno era limitada. En tercer lugar, incluso si los agentes de la vida silvestre pudieran montar un plan eficaz para arrestar a quienes no cumplieran la prohibición, no estaba tan claro que los niveles más altos del gobierno provincial darían luz verde a dichos arrestos, arriesgando el proyecto Lower Churchill.

En este contexto - argumentamos-, colaborar con la nación innu para abordar el problema en los términos definidos por los ancianos innu tenía más probabilidades de obtener mejores resultados - incluso en los términos definidos por los administradores de la vida silvestre - que las que la prohibición tendría. Demandar y monitorear que los cazadores siguieran el protocolo innu tendría un amplio apoyo en las comunidades y, consecuentemente, se cazarían menos animales. Después de la conversación en diciembre de 2012, los agentes locales de vida silvestre estaban considerando la posibilidad de elevar la propuesta a la cadena de mando. Pero entonces, en enero de 2013 y bajo la presión del público, la prohibición fue emitida desde arriba de la jerarquía ministerial. Como habíamos pronosticado, miembros de la comunidad fueron a cazar a pesar de la prohibición y el gobierno provincial fue reacio a hacerla cumplir por medio de arrestos. Agentes de vida silvestre monitorearon la caza desde helicópteros, pero no hubo detenciones relacionadas con la caza.

La moraleja de la historia —o su relación con otra cosmopolítica — es que por un momento nosotros y los agentes de vida silvestre produjimos lo que Viveiros de Castro (2004) llama «traducción como equivocación controlada» (translation 
as controlled equivocation). La traducción como equivocación controlada se basa en la noción contraintuitiva de que lo que hay que mantener en el primer plano cuando se traducen dos términos diferentes es, precisamente, su diferencia. Esta idea contrasta tanto con la expectativa usual de que la traducción debe esforzarse por establecer la equivalencia entre dos términos a través de un referente común preexistente, y también la idea alternativa de que una buena traducción crea un nuevo referente común. En el primer caso, la traducción resuena con la presunción de una realidad fáctica ya existente. En el último caso, la traducción se convierte en un proyecto para componer progresivamente una realidad fáctica con asuntos de interés y de cuidado. Sin embargo, en ambos casos el supuesto es que lo que conecta y hace posible una traducción (y una relación sostenida) entre los términos es un «terreno común».

En nuestro caso, en lugar de esforzarnos por descubrir o generar un «terreno común», buscamos hacer posible un conjunto de acciones que eran homonímicas: es decir, se dirigían simultáneamente a diferentes «cosas». Promover y hacer cumplir el protocolo adecuado de nataun (el cuidado de atîku) también significaba la caza de un menor número de animales (el cuidado del caribú); ni los cazadores innu ni los administradores de vida silvestre tenían que subordinar sus propias prácticas de cuidado. De hecho, en esta «traducción», el cuidado de caribú y atîku se habría reforzado entre sí. A pesar de que la prohibición evitó las manifestaciones futuras de esta traducción, mientras duró constituyó un buen ejemplo de cómo la cosmopolítica podría estar orientada de forma activa por un vector distinto del «mundo común». En este caso, lo «no común», la diferencia, en definitiva, lo «equívoco» fue un vector productivo también. E insisto en la palabra también porque no es una cuestión de uno u otro, sino de ambos. Hay aquí un terreno fecundo para continuar desarrollando otras potencialidades de la cosmopolítica ${ }^{25}$.

25 En este punto puede ser importante enfatizar que, cuando hablo de cosmopolíticas orientadas a un mundo común («cosmopolitics oriented to the common world»), estoy indicando que la cosmopolítica gana peso como problemática en relación con el mundo común. Pero esto no es necesario, específicamente en el caso de Stengers, cuyo concepto de ecología de las prácticas («ecology of practices») no sería contrario a hacer activamente («doing») divergencias como un movimiento cosmopolítico. 


\section{REFERENCIAS BIBLIOGRÁFICAS}

Armitage, Peter (1992). Religious Ideology Among the Innu of Eastern Quebec and Labrador. Religiologiques, 6, 64-110.

Armitage, Peter (2010). Innu of Labrador Contemporary Land Use Study. Innu Nation: Labrador. Disponible en http://www.env.gov.nl.ca/env/env_assessment/projects/Y2010/1407/1_i_t_1_ea_aboriginal_cs_app_a.pdf

Barad, Karen (2007). Meeting the universe halfway: Quantum physics and the entanglement of matter and meaning. Durham, NC: Duke University Press.

Blaser, Mario (2009). The Threat of the Yrmo: The Political Ontology of a Sustainable Hunting Program. American Anthropologist, 111(1), 10-20.

Blaser, Mario (2013a). Armitage, Peter (Notes Towards a Political Ontology of «Environmental» Conflicts. En Lesley Green (ed.), Contested Ecologies: Nature and Knowledge. Cape Town: Human Sciences Research Council of South Africa Press.

Blaser, Mario (2013b). Armitage, Peter (Ontological Conflicts and the Stories of Peoples in Spite of Europe. Current Anthropology, 54(5), 547-568.

Blaser, Mario (2014). Ontology and indigeneity: on the political ontology of heterogeneous assemblages. Cultural Geographies, 21(1), 49-58.

Carrithers, Michael, Matei Candea, Karen Syke, Martin Holbraad y Soumhya Venkatesan (2010). Ontology is just another word for culture. Critique of Anthropology, $30(2), 152-200$.

Castro, Damian (2015). Meating the Social: Caribou Hunting and Distribution in Sheshatshiu, Labrador. Unpublished doctoral dissertation. Department of Anthropology, Memorial University of Newfoundland.

Coole, Deborah \& Samantha Frost (eds.) (2010). New Materialisms: Ontology, Agency, and Politics. Durham, NC: Duke University Press.

De la Bellacasa, Maria Puig (2011). Matters of care in technoscience: Assembling neglected things. Social Studies of Science, 41(1), 85-106.

De la Cadena, Marisol (2010). Indigenous cosmopolitics in the Andes: Conceptual reflections beyond «politics». Cultural Anthropology, 25(2), 334-370.

Descola, Philippe (2013). Beyond nature and culture. University of Chicago Press.

DiNovelli-Lang, Danielle (2013). The return of the animal: Posthumanism, indigeneity, and anthropology. Environment and Society: Advances in Research, 4(1) 137-156.

Gad, Christopher, Casper Bruun Jensen y Brit Winthereik (2014). Practical ontology: Worlds in STS and anthropology. NatureCulture, 3, 67-86. 
Government of Canada (2012). Government of Canada Response to the Report of the Joint Federal-Provincial Review Panel for Nalcor's Lower Churchill Generation Project in Newfoundland and Labrador. Disponible en http://www.ceaa-acee. gc.ca/050/documents/54772/54772E.pdf

Haraway, Donna (1988). Situated Knowledges: the Science Question in Feminism and the Privilege of Partial Perspective. Feminist Studies, 14(3), 575-599.

Haraway, Donna (2008). When species meet. Minneapolis, MN: University of Minnesota Press.

Haraway, Donna (2015). Anthropocene, Capitalocene, Plantationocene, Chthulucene: Making kin. Environmental Humanities, 6, 159-165.

Henriksen, Georg (1973). Hunters in the Barrens. St. John's: ISER.

Henriksen, Georg (2008). I dreamed the animals: Kaniuekutat: The life of an Innu hunter. Nueva York: Bergham Books.

Holbraad, Martin (2007). The power of powder: multiplicity and motion in the divinatory cosmology of Cuban Ifá (or mana again). En A. Henare, S. Wastell y M. Holbraad (eds.), Thinking through things: Theorising artefacts ethnographically (pp.189-225). Milton Park y Nueva York: Routledge.

Holbraad, Martin, Morten Axel Pedersen y Eduardo Viveiros de Castro (2014). The politics of ontology: Anthropological positions. Cultural Anthropology Online.

Joint Review Panel (2011). Hearing held at Sheshatshiu Innu School. Tuesday, March 22, 2011 Volume 17. Disponible en http://www.ceaa.gc.ca/050/ documents/48945/48945F.pdf

Joint Review Panel Report (2011). Lower Churchill Hydroelectric Generation Project. Nalcor Energy Newfoundland and Labrador. Disponible en http://www.env.gov. nl.ca/env/env_assessment/projects/Y2010/1305/lower_churchill_panel_report. pdf

Kirksey, Stefan y Stefan Helmreich (2010). The emergence of multispecies ethnography. Cultural Anthropology, 25(4), 545-576.

Kohn, Eduardo (2015). Anthropology of Ontologies. Annual Review of Anthropology, 44, 311-327.

Latour, Bruno (1993). The Pasteurization of France. Cambridge, MA: Harvard University Press.

Latour, Bruno (1999). Pandora's hope: Essays on the reality of science studies. Cambridge, MA: Harvard University Press.

Latour, Bruno (2004b). Why has critique run out of steam? From matters of fact to matters of concern. Critical Inquiry, 30(2), 225-248. 
Latour, Bruno (2004c). Politics of nature: How to bring the sciences into democracy. Cambridge, MA: Harvard University Press.

Latour, Bruno (2007). Turning around politics: A note on Gerard de Vries's paper. Social Studies of Science, 37(5), 811-820.

Latour, Bruno (2014). ¿El cosmos de quién?, ¿qué cosmopolítica? Comentarios sobre los términos de paz de Ulrich Beck. Revista Pléyade, 14, 43-59.

Law, John (2009). Actor Network Theory and Material Semiotics. En Brian S. Turner (ed.), The New Blackwell Companion to Social Theory. Oxford, UK: WileyBlackwell.

Mol, Annemarie (2002). The body multiple: Ontology in medical practice. Durham NC: Duke University Press.

Newfoundland and Labrador Wildlife (2010). George River Caribou Management. http://www.env.gov.nl.ca/env/wildlife/pdf/GRCH_2010_Consultations.pdf

Pedersen, Morten (2007). Talismans of thought: shamanist ontologies and extended cognition in northern Mongolia. En A. Henare, S. Wastell y M. Holbraad (eds.), Thinking through things: Theorising artefacts ethnographically (pp. 141-167). Milton Park y Nueva York: Routledge.

Povinelli, Elizabeth (2001). Radical worlds: The anthropology of incommensurability and inconceivability. Annual Review of Anthropology, 30(16), 319-335.

Povinelli, Elizabeth (2002). The cunning of recognition: Indigenous alterities and the making of Australian multiculturalism. Durham NC: Duke University Press.

Samson, Colin (2003). A way of life that does not exist: Canada and the extinguishment of the Innu. Londres: Verso.

Samson Colin y Elizabeth Cassell (2013). The long reach of frontier justice: Canadian land claims «negotiation» strategies as human rights violations. The International Journal of Human Rights, 17(1), 35-55.

Stengers, Isabelle (1996). Pour en finir avec la tolérance. Cosmopolitiques VII. París: La Découverte, Les Empécheurs de Penser en Rond.

Stengers, Isabelle (2000). The invention of modern science. Minneapolis, MN: University of Minnesota Press.

Stengers, Isabelle (2014). La propuesta cosmopolitica. Revista Pléyade, 14, 17-41.

Tsing, Anna (2012). Unruly edges: mushrooms as companion species. Environmental Humanities, 1(2012), 141-154.

Viveiros de Castro, Eduardo (2004). Perspectival Anthropology and the Method of Controlled Equivocation in Tipit'1. Journal of the Society for the Anthropology of Lowland South America, 2(1), 3-22.

Viveiros de Castro, Eduardo (2012). Cosmological perspectivism in Amazonia and elsewhere. HAU: Masterclass Series, 1, 45-168. 